\title{
Socio-psychological aspects of innovation behavior of workers in construction organizations
}

\author{
Mikhail Leontev ${ }^{*}$ \\ Moscow State University of Civil Engineering, Yaroslavskoe shosse, 26, 129337, Moscow, Russia
}

\begin{abstract}
The ability for introduction of innovation, improve products, services and work processes is becoming increasingly important for the construction industry today. This paper focuses on the personal and sociopsychological characteristics of innovation: employee attitudes toward innovations, the degree of employee involvement in innovation activity, personal motivation and incentives. It was found that the innovative behavior of workers in construction organizations is positively influenced by: participative leadership style, support of employees' innovative behavior on the part of management, external business contacts, innovative results, successful practice of introducing innovations in the firm (enterprise). These factors, combined with material incentives, the desire for self-realization, the involvement of employees in all stages of the innovation process, create a suitable environment for the innovative activity of employees.
\end{abstract}

\section{Introduction}

In the modern world, the innovative behavior of employees can be seen as an important component of the success of any organization. Innovative behavior of the employee is significant for different areas of activity, its stimulation is one of the ways to increase the competitiveness of an industrial enterprise.

One of the directions of the innovative development of an organization emphasizes the need to transform into the main capital the abilities of employees to innovate. According to P. de Jong and D. den Hartog, it is the employees of an organization that can help to increase the productivity of their company due to the ability to generate new ideas and implement them in order to produce better products, offer professional service and improve the work process [1]. Thus, only organizations that are aware of the value of human capital, capable of transforming their activities in accordance with the changes that are occurring, can claim high results.

The ability to continuously innovate and improve products, services and work processes is now crucial to organizations. Employees should be both ready and able to innovate, if a continuous stream of innovations is implemented. The actions of individual employees are crucial for continuous innovation and improvement, this is stated in the scientific literature

\footnotetext{
Corresponding author: miillen@ @rambler.ru
} 
on innovation, but is also highlighted in the work on several popular management principles, general quality management and in corporate entrepreneurship [2].

T. Peters has found out that successful firms use special systems of indicators, which is an effective lever of influence of managers on innovative activity of employees. Its indicators turn into real benchmarks, which are better than any directions "from above" to help middle and lower-level managers in the field make decisions about the allocation of resources, and ultimately determine the company's innovative strategy [3].

The study of the problem of innovative behavior of employees in an organization is quite active. The analysis of scientific literature has shown the diverse positions of researchers in relation to the understanding of innovation and innovative behavior, the study of innovative behavior of employees is aimed primarily at the social aspects of innovative behavior (focus on obtaining results, dependence on the opinions of others, the requirements of the quality management system, etc.). Only a small part of research in the field of innovative behavior is aimed at studying its personal components.

Employee innovations were studied in terms of personality characteristics, results and behavior. Innovative behavior at work usually involves exploring opportunities and generating new ideas (creativity-related behavior), but it can also include behavior aimed at implementing change, applying new knowledge or improving processes to enhance personal and/or group activities (implementation-oriented behavior). In many papers, the focus was on the creativity of employees and the creation of new ideas in the early stages of innovation process. M. Mumford called for more attention to the introduction of ideas [4].

Theories of innovation have repeatedly stressed that innovation is broader than creativity, and also includes the realization of ideas. The innovative behavior of employees not only includes the creation of ideas, but also the behavior necessary to realize ideas and achieve improvements that will enhance personal and/or business productivity [5].

Innovative behavior is closely related to creativity in workplaces. Creativity is defined as the production of new and useful ideas relating to products, services, processes and procedures. The carried out analysis of scientific works has shown that activation of integration of components of creative resources of an employee allows to significantly increase the efficiency of the directed processes of creating innovative products, as well as rational use of the creative abilities of each employee of an enterprise, its internal, "hidden" potential [6]. Unlike creativity, the innovative behavior of employees is clearly aimed at gaining some kind of benefit. It has a clearer practical component and is expected to lead to the creation of innovative products. Creativity can be seen as an essential component of innovative employee behavior, most evident at the beginning of the innovation process, when problems or productivity gaps were discovered and ideas were generated in response to the perceived need for innovation [7].

Some researchers argue that innovation is a personal characteristic of an employee, the creative potential of the individual is on the first place, others adhere to the behavioral approach, speaking of individual innovative behavior.

The innovative behavior of workers as a complex phenomenon is reflected in the various methodological positions of authors who stand on the positions of determinism (O. Janssen, F. Yuan, R. Woodman, etc.) and system methodology [8]. The innovative behavior of an employee reflects his (her) personal characteristics, represents a set of his (her) active activities aimed at initiating, generating, implementing and applying useful innovative ideas to improve the working environment or system at any organizational level, and these actions go beyond the expected, prescribed scope of their working roles. But with a large number of considered factors of the innovator's behavior of an employee, consistent classification in the scientific literature is not given. The approach to innovative, success-oriented behavior, according to F. Yuan and R. Woodman, is one of the most popular. In the framework of this approach, it is considered that the employees of the organization make a deci- 
sion regarding the implementation of innovations in order to increase the efficiency of their activities, from the implementation of innovations they expect positive results. Therefore, innovations will be beneficial both for the organization and for individual employees.

According to N. King and N. Andersen, each innovation process passes through two main stages: the stage of initiation, or the birth of ideas, and the stage of realization, or the introduction of ideas. Innovative behavior is aimed at the implementation by employees of an organization of new ideas, products, processes, procedures that can be applied to optimize work within a certain position, group or organization as a whole. N. King and N. Andersen also note the multidimensional nature of innovative behavior [9].

Innovations are considered by $\mathrm{O}$. Janssen as a social process that can cause opposition of other employees of the organization, committed to the existing system of views and actions; innovation does not form part of the institutional system that has been established in modern society. Thus, in order to be a successful innovator, it is necessary to acquire the support of colleagues, superiors or sponsors in protecting and promoting new ideas. The employee of the organization will invest more efforts in innovation, development, introduction of new ideas, if he has control over the events [10].

Innovative behavior is not only aimed at creating and implementing new ideas, but also depends on a certain culture or mentality of employees of all levels. To maximally include workers in innovation activities, the most optimal is to find a balance between the traditional and complex paradigms of quality systems, the availability of psychological contracts, an effective feedback system with clear and transparent criteria, teamwork and cooperation between departments [11].

Another area in the study of innovative behavior developed by S. Scott and R. Bruce [12]. They consider innovative behavior in conjunction with creative behavior aimed at developing ideas that are new and useful. S. Scott and R. Bruce have operationalized innovative behavior as a multi-stage process and distinguished three components of innovative behavior: 1) identifying new opportunities; 2) the generation of ideas; 3) promotion and implementation of ideas.

The beginning of the innovation process is often determined by chance: the discovery of opportunities, a new problem or task that should be solved.

The generation of ideas can relate to new products, services or processes, the emergence of new markets, the improvement of existing production processes or, in general, the solution of emerging problems. Generating ideas often involves rearranging existing parts, combining them, new combinations often serve as the basis for a scientific discovery.

After the ideas are created, their promotion and realization are necessary. In most cases, it is not clear whether the benefits of ideas will exceed the costs of their development and implementation, as well as the expected resistance to change. In many cases, potential consumers of innovative products (colleagues, managers, customers, etc.) may not be sure of their value, and such products should be "sold" to users. Being in an informal role, innovator promotes the creative idea, should make efforts for its implementation. Promotion of ideas involves seeking support and creating coalitions, with the goal of persuading and receiving approval from other employees or management, as well as consultations and negotiations. Finally, the supported idea should be put into practice. Significant efforts and attitudes towards the final result are required from the employees, so that the realized idea turns into a practical proposal. Therefore, innovations in the future inevitably become part of the production process.

Consider the socio-psychological factors that affect the innovative behavior of an employee. The first factor is the participative management style. Participatory management can be seen as a process in which workers and other categories of personnel have the right to make managerial decisions within the enterprise. Participative management style can take various forms, including consultations, joint decision-making and delegation of author- 
ity [13]. Participative management style increases the individual sense of selfdetermination, control and responsibility for the assigned task, as well as the level of internal motivation of an employee for the task. This is expected to lead to higher levels of employee innovation behavior. A significant contribution to the development of ideas of participatory management was made by such scientists as K. Alderfer, F. Herzberg, D. McClelland, A. Maslow, E. Mayo. In the United States, participatory management began to be considered within the framework of the school of human relations, special attention was paid to D. Garson, A. Berli, M. Minze, E. Lowler [14].

In a number of studies it was found that the leaders of highly creative teams actively participated in decision-making and worked together with the team to determine priorities and purposes, supporting the innovative behavior of employees.

The potential role of external business contacts of employees in the development of innovative behavior of employees is less often studied today. External business contacts can become valuable sources of information from customers, suppliers, knowledge institutions and competitors. We expect that workers with more frequent and diverse external business contacts will show more innovation. For example, a meeting of specialists who work in different organizations, the existence of close contacts with suppliers and customers gives an opportunity to receive feedback about products or services and develop ideas for their improvement. Interaction of diverse subjects and information help realize creative abilities and find professional and material support for the implementation of plans.

It is assumed that the innovative behavior of employees is influenced by various forms of successfully implemented innovative results, for example, more suggestions for innovation and ideas for social change, as well as innovations that have been implemented to the greatest extent in practice in the form of new products and processes. Individuals in positions higher than line managers are expected to demonstrate more innovative products in these conditions.

The purpose of the study was to determine the socio-psychological aspects that affect the innovative behavior of employees in construction organizations.

To achieve the purpose of the study, it was necessary to solve the following tasks: identify the personal and socio-psychological characteristics of innovation: the attitude of employees to innovation, the degree of involvement of employees in innovation, personal motives and incentives, factors related to practical issues of promoting and introducing innovations in enterprises, their influence on the work process.

On the basis of the above, the research hypothesis was formulated: the innovative behavior of workers in construction organizations is positively influenced by: participative leadership style, support of innovative management behavior by employers, external business contacts, innovative results, successful innovation practice in the enterprise (firm).

\section{Materials and methods}

The study was conducted in medium-sized construction companies. The study involved 74 mental employees with higher education (for example, engineers, architects, economists, IT) and their sipervisors. 59\% of the respondents are men, $41 \%$ are women. These employees have (had) a direct relationship to the creation, development and implementation of new products or processes.

The research method was a semi-structured survey. The forms of the questionnaire were sent by e-mail, within a period of two weeks, 74 responses were received.

Proceeding from the fact that the respondents are directly involved in the development, implementation and technology of producing of new products and services, their opinion should be considered competent for the issues of innovative activities. The auxiliary personnel of firms and persons without higher education did not take part in the survey. 
Initially, a survey was conducted to identify the attitude towards innovation of enterprise employees, in particular, regarding the stages of innovative behavior, in order to establish the involvement of workers in it: identifying new opportunities, generating ideas, promoting and realizing ideas. Examples of statements:

You are interested in how you can improve processes and procedures that are not part of your daily responsibilities (identifying new opportunities); you are developing original solutions to problems (generating ideas); you are trying to convince colleagues to support innovative idea (promotion and implementation of ideas).

The degree of approval by the respondents of the participative leadership style was measured using 8 points that elicited the perception by employees of the issues of encouraging the leader of their autonomy, as well as joint decision-making [15].

Respondents noted the degree of their agreement with the statements of this scale and the subsequent ones, from 0 to 10 points ("absolutely disagree" - "completely agree"). An example of the statement: "My boss is interested in my opinion on the issues of work".

To measure external business contacts, a scale of 6 points was used. Various actors in the process, such as competitors, knowledge institutions and enterprises can accelerate the innovation process and become a source of opportunities. The points of the scale contained statements about contacts with clients, employees of other companies, knowledge institutions and enterprises, as well as visits to conferences. These scales were developed on the basis of De Jong \& Den Hartog "functional sources of innovation" and modified by the author. Example of the statement: "I attend conferences, exhibitions, seminars outside the organization".

The next three scales consisted of 6 points each. The self-assessment scale of innovation results of employees considered the frequency of employees' proposals and the introduction of new products and services, working methods, proposals for knowledge sectors and markets (customer groups). These are well-known objects of innovation [16]. Examples of statements: "At work, I contribute to the development of new products and services".

The scale of support of innovative behavior of employees on the part of management made it possible to identify methods of stimulating employees at the stage of promotion and implementation of ideas. The scale of successful practice of introducing innovations in the firm (organization) revealed the activity of the organization and the measures to introduce new products and services.

Examples of statements: "In our organization, a system of encouraging the innovative activity of employees has been developed." "Our company has established a procedure for introducing new products and services."

\section{Results}

For each measurement scale used in this study, a one-dimensionality was established using research factor analysis [17]. For each scale, at least $60 \%$ of the variance for the first factor was taken into account. The results of the analysis speak in favor of one-factor solutions. The coefficient of Alfa Cronbach was 0.88 for participatory leadership, 0.81 for supporting the innovative behavior of employees on the part of management, 0.83 for external business contacts, 0.79 for self-assessment of innovation results, 0.85 for successful practice of introducing innovations in this firm, with an average correlation above 0.40 .

The majority of respondents $(65 \%)$ have a more or less positive attitude to innovation (they approve or are generally positive), while a large proportion of women (38.8\% of the total number of respondents compared to $29.3 \%$ for men). Among the age categories, the largest share of positive answers belongs to women from 26 to 35 years old (9\% of the total number of respondents). Negative attitudes towards innovation were mostly shown by men $16.1 \%$ of the total number of respondents and $11.4 \%$ - women; the largest proportion for men from 36 to 45 years $-7.9 \%$ of the total number of respondents. 
Among respondents, 58\% are ready to participate in various stages of innovation activity in one way or another: they are ready to take part in identifying new opportunities $45 \%$, generating ideas $-67 \%$, promoting and implementing ideas $-31 \%$ of the total number of respondents. At the same time, $35 \%$ of women and $27 \%$ of men are ready to take part in all three stages of innovation activity, in the age groups the greatest proportion was shown by women aged from 26 to $35-9.8 \%$ of the total number of respondents.

Negative attitudes towards participation in innovation processes were expressed: men $16.7 \%$ of the total number of respondents, women $-15.2 \%$ of the total number of respondents. $24.8 \%$ of respondents said that they did not practice innovations at all and did not participate in innovation activities.

Most respondents believed that innovations had a positive impact on their work (62\%), $15 \%$ believed that innovation had a rather negative impact on their work.

Among the main motives for creating innovative products and processes, respondents noted the possibility of their self-realization $(78 \%)$, the main incentives for their creation and promotion were material, financial $(38 \%)$, career growth and recognition of merit $(29 \%)$, management encouragement $-18 \%$ of the total number of respondents.

Below are the average values on the scales of the questionnaire: participative leadership style -7.1 ; external business contacts -6.5 ; self-assessment of innovative results -6.4 ; support for innovative employee behavior by management -7.4 ; successful practice of introducing innovations in the organization (firm) - 5.3. The standard deviation (SD) for these scales was, respectively: $0.92 ; 1.71 ; 1.43 ; 0.47 ; 1.27$.

\section{Discussions}

The results show that women are most active in the willingness to participate in innovations (the largest proportion of women aged 26 to 35 years), the main motivation for employees is the desire for self-realization, and the main incentives are the material (financial) aspect, the opportunity for career growth and encouragement from management.

The activity of an innovator has its own specifics. Since innovative activities are of an intellectual nature, the motives and incentives to it will also depend on the intellect. Our research confirms that self-realization is the main motive for enterprise employees who are directly connected with innovation activity. The same opinion is held N. Doerner considering innovations as a component of intellectual labor activity and its motivation, aimed at creating new or improving existing processes, ways, products and methods, one of the motives of which is the worker's need for self-realization". Among the most significant are the material (financial) factor [18].

In sum, based on the results obtained in the study, we believe that the hypothesis of our study on the main socio-psychological factors of the employees' innovative behavior has been confirmed. It can be summarized that management support and feedback, training and development of employees, creating conditions for the exchange of knowledge with the external environment, participative leadership style innovation results and successful innovation practice create a suitable environment for the employee's innovative activity, along with material incentives and aspirations employee to self-realization, expressed in innovative work and reflecting the specifics of innovative work as an intellectual one.

The data obtained correspond to the data of J. Stoffers [11]. It was shown the positive impact of external business contacts of employees on their innovation activities. Effective managers have used, to a large extent, counseling and delegation of authority to encourage employees and provide them with a sense of responsibility for their actions and decisions, which has prompted them to generate ideas and implement them. According to J. Park et al., there were significant correlations between the innovative behavior of employees and independent assessments (external assessments) of innovation discoveries, the existence of practice of introducing innovations in the organization. This is confirmed in a study con- 
ducted among engineers, and such correlations were found. Innovative behavior is facilitated by the following factors: 1) attention of the company's management to issues of development and innovation; 2) application of targeted and permanent methods of change (results management); 3) constant feedback process and desire to learn; 4) encouragement for development [19].

But, despite the positive attitude of the employees in general to innovations and participation in innovation activities, there are some negative factors that negatively affect the desire of the employees of the enterprise to participate in innovation activities. In particular, such factors include the imperfection of the system for supporting the innovative activity of employees, the lack of clear mechanisms for the implementation of innovations, the reluctance of management to participate in the innovation process, the high frequency of changes, and the insufficient financing of innovation.

As a mechanism to facilitate change, regular studies of the organizational climate, meetings of various working groups on joint activities, planning of reforms, targeted performance evaluations, periodic visits of external consultants and encouragement for successful innovations can be used.

\section{Conclusion}

The results of the study allow us to confirm the influence of socio-psychological factors that determine the innovative behavior of workers in construction organizations.

Innovative activity of employees is crucial for the functioning of many firms. An organization that depends very much exclusively on plans for prescribed behavior is a very fragile social system. This research contributes to a better understanding of the innovative behavior of workers and their correlates. Relying on work on innovative behavior and creativity of employees, stages of innovative activity were offered: research of opportunities, generation of ideas, promotion and implementation.

Summarizing the results of this study, we have selected personal and sociopsychological aspects that positively affect the innovative behavior of workers in the construction organization.

Management support and feedback, training and development of employees, creation of conditions for knowledge sharing, leadership behavior of supervisors and successful innovation practice create an appropriate environment for employees' innovation, combined with material incentives and employees' aspirations for self-fulfillment expressed in intellectual innovative work.

In addition to innovative results and measurements related to the work context, other characteristics of an individual, working environment and the group can become areas of future research for the study of innovation. For example, these characteristics may be related to the work context, other personal qualities, working environment and the group. Studies are also needed in those contexts where innovation and day-to-day work do not match content (in other words, where innovative efforts of all employees are needed, not just those who are engaged in innovative workplaces).

\section{References}

1. J.P.J. de Jong, D.N. den Hartog, How Leaders Influence Employees' Innovative Behaviour, European Journal of Innovation Management, 10, 1 (2007) Pp. 41-64

2. N. Anderson, K. Potonik, J. Zhou, Innovation and Creativity in Organizations: A State-of-the-Science Review and Prospective Commentary, Journal of Management, 40, 5 (2014) Pp. 1297-1333

3. T. Peters, R. Waterman. In Search of Perfection: Lessons of America's Most Successful Companies (Moscow: Alpina Pablisher, 2018) 
4. M.D. Mumford, B. Licuanan, Leading for Innovation: Conclusions, Issues, and Directions, Leadership Quarterly, 15, 1 (2004) Pp. 163-171

5. A.M. Mukhamedyarov. Innovative management: Textbook. (Moscow: SRC INFRA-M, 2014)

6. E.M. Guzeeva, Development of personnel creativity in business structures on the basis of intra-organizational behavior, Creative Economy, 10, 34 (2009) Pp. 27-32

7. Technology for Creativity and Innovation: Tools, Techniques and Applications..., (Ed. by A. Mesquita, N.-Y., Hershey, 2011)

8. F. Yuan, R.W. Woodman, Innovative behavior in the workplace: the role of performance and image outcome expectations, Acad. of Management Jour., 53, 2 (2010) Pp. 323-342

9. F. Monaco, V.N. Guimarães, Creativity and Innovation in the Context of Team-work: an Evaluation in the Self-management Cells and Quality Control Circles of Ambev S.C. Branch, Brazilian Administration Review, 4, 1 (2007) Pp. 21-34

10. O. Janssen, How fairness perceptions make innovative behavior more or less stressful, Journal of Organizational Behavior, 25, 2 (2004) Pp. 201-215

11. J. Stoffers, P. Neessen, P.van Dorp, Organizational culture and innovative work behavior: A case study of a manufacturer of packaging machines, American Journal of Industrial and Business Management, 5, 4 (2015) Pp. 198-207

12. S.G. Scott, R.A. Bruce, Determinants of innovative behavior: A path model of individual innovation in the workplace, Acad. of Management Jour., 37 (1994) Pp. 580-607.

13. K. Laursen, N.J. Foss, Human Resource Management Practices and Innovation, The Oxford Handbook of Innovation Management (Ed. by M. Dodgson, D.M. Gann, N. Phillips), Pp. 505-529

14. V.F. Potundanskaya, E.O. Alifer, Development of participative management in industrial enterprises, Journal of Creative Economy, 10, 2 (2016) Pp. 197-210

15. S.N. Glagolev, Yu.A. Doroshenko, V.V. Moiseev. Actual problems of investment and innovations in modern Russia. Monograph (Moscow: Direct Media, 2014)

16. S.A. Shane. A General Theory of Entrepreneurship: The Individual-Opportunity Nexus (Aldershot, UK: Edward Elgar, 2003)

17. D. Lowley, A. Maxwell. Factor analysis as a statistical method (Moscow, 2012)

18. N. Doerner, O. Gassmann, F.M. Morhart. Innovative Work Behavior: The Roles of Innovative Self-Efficacy and Transformational Leadership, $18^{\text {th }}$ International Product Development Management Conference, Delft, Netherlands, 2011

19. J. Park, K.H. Lee, P.S. Kim, Participative Management and Perceived Organizational Performance: The Moderating Effects of Innovative Organizational Culture, Public Performance \& Management Review, 39, 2 (2016) Pp. 316-336 